\title{
Studies of the competing rates of catechol oxidation and suicide inactivation of tyrosinase
}

\author{
Christopher A. Ramsden ${ }^{a,}$ and Patrick A. Riley ${ }^{b}$ \\ ${ }^{a}$ Lennard-Jones Laboratories, School of Physical and Geographical Sciences, Keele University, \\ Staffordshire ST5 5BG, United Kingdom \\ ${ }^{b}$ Totteridge Institute for Advanced Studies, The Grange, Grange Avenue, London N20 8AB, \\ United Kingdom \\ E-mail: c.a.ramsden@chem.keele.ac.uk
}

\begin{abstract}
Tyrosinase oxidation of catechols to ortho-quinones is accompanied by suicide inactivation of the enzyme. The rates of these competing processes vary and depend on the nature of ring substituents. For a series of 4-substituted catechols the relationships between structure and reaction rates have been examined using multiple regression. Significant but different structurerate relationships were found for each process. The oxidation rate $\left(k_{1}\right)$ is greatest for short hydrophobic substituents; there is an optimum substituent hydrophobicity $(\pi \sim 0.7)$ for the rate of inactivation $\left(\mathrm{k}_{2}\right)$.
\end{abstract}

Keywords: Tyrosinase, regression analysis, oxidation rates, catechols, suicide-inactivation

\section{Introduction}

The enzyme tyrosinase (EC 1.14.18.1) occurs widely in nature and one of its functions is the oxidation of tyrosine to dopaquinone in the biosynthetic pathway to the melanin pigments. ${ }^{1,2}$ In addition to this mono-oxygenase activity (phenols $\rightarrow$ ortho-quinones), tyrosinase is unusual in that it can also function as an oxidase and oxidises catechols $\mathbf{1}$ to ortho-quinones $\mathbf{2}$ by a subtly different mechanism. ${ }^{2}$ Because tyrosinase is uniquely expressed in pigment-generating cells and is up-regulated in the majority of pigment cell tumours it has been proposed as a targeting strategy for selective chemotherapy for malignant melanoma. ${ }^{3}$ However, although catecholic substrates are generally more readily oxidised by tyrosinase, the situation is complicated by the fact that oxidase activity of tyrosinase (catechols $\rightarrow$ ortho-quinones) is accompanied by enzyme inactivation (suicide inactivation) which would seriously compromise any therapeutic action.

The suicide inactivation associated with oxidation of catechols has been known for many years ${ }^{4,5}$ but the mechanism remained unknown. We have recently provided evidence that this inactivation occurs when the catecholic substrate presents itself to the active site as a phenolic 
substrate, ${ }^{6-9}$ leading to irreversible reductive elimination of copper $^{10}$ from the enzyme. During the course of these studies we have examined a number of 4-substituted catecholic substrates and have measured rate constants for their oxidation $\left(\mathrm{k}_{1}\right)$ and for the rates at which they inactivate the enzyme $\left(\mathrm{k}_{2}\right)$ (Scheme 1). In this paper we describe quantitative relationships between catechol structure and the rate constants $\mathrm{k}_{1}$ and $\mathrm{k}_{2}$, and demonstrate how the nature of the substituent influences the relative rates of the competing processes shown in Scheme 1.

inactivated tyrosinase

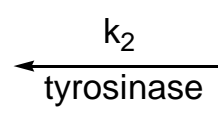<smiles>[R]c1ccc(O)c(O)c1</smiles>

1

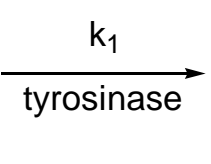

Scheme 1. Competing oxidase $\left(\mathrm{k}_{1}\right)$ and inactivation $\left(\mathrm{k}_{2}\right)$ reactions of tyrosinase.

\section{Results and Discussion}

We examined the oxidation by tyrosinase from Agaricus bisporus of a series of catecholic substrates and measured the initial oxidation rates and the total oxygen utilization by polarimetry. The kinetics of oxygen utilization by the catechols 1a-g (see Table 1), adjusted to give equivalent initial oxidation rates, are shown in Figure 1(a) and demonstrate significant variation in the relative inactivation rates resulting in different total oxygen uptake.

(a)

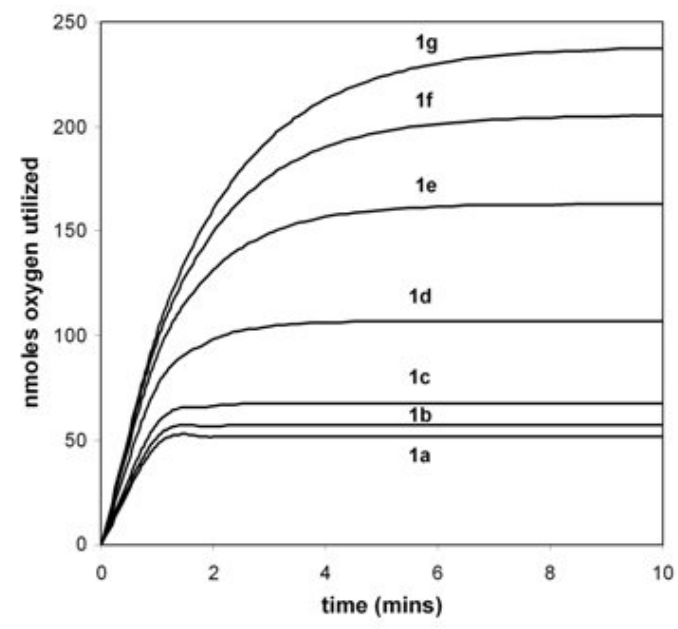

(b)

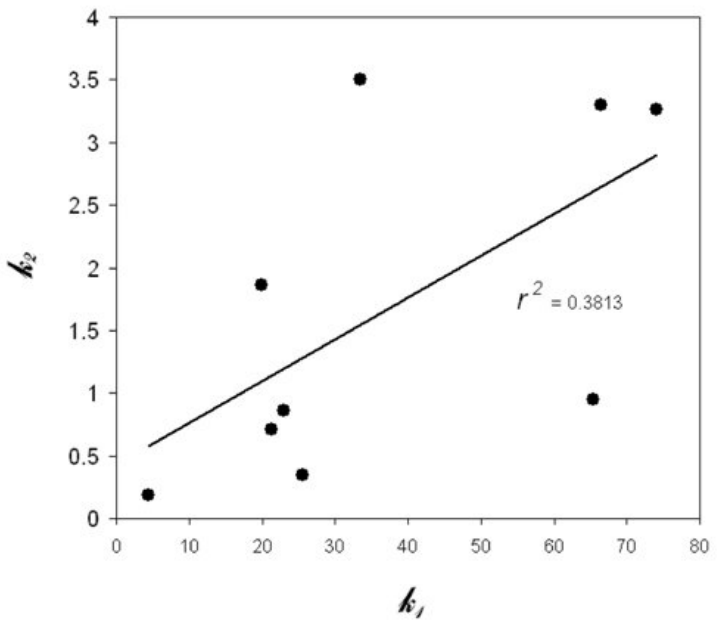

Figure 1. (a) Comparative oxygen utilization kinetics for the catechols 1a-g adjusted for equivalent initial oxidation rates; (b) Scatter plot of initial oxidation rate $\left(\mathrm{k}_{1}\right)$ versus the inactivation rate $\left(\mathrm{k}_{2}\right)$. 
A plot of the $\mathrm{k}_{1}$ and $\mathrm{k}_{2}$ values (Figure $1(\mathrm{~b})$ ) failed to indicate any correlation between the oxidation rate and the inactivation rate. The linear correlation coefficient $\left(r^{2}=0.381\right)$ is nonsignificant suggesting that different reactions are involved.

To investigate the effect of substitutent groups on the oxidation and inactivation rates a multiple regression analysis was carried out. Values of $\log \mathrm{k}_{1}$ and $\log \mathrm{k}_{2}$ for thirteen catechols 1a-m are shown in Table 1 together with the substituent parameters used in the analysis. The catechol substituents (R) were chosen to give a good variation of steric, electronic and hydrophobic properties. ${ }^{11}$

Table 1. Rate constants $\left(\log \mathrm{k}_{1}\right.$ and $\left.\log \mathrm{k}_{2}\right)$ and structural parameters for catechols $\mathbf{1}$

\begin{tabular}{cccccccccccc}
\hline Catechol & Substituent & $\log \mathrm{k}_{1}$ & $\log \mathrm{k}_{2}$ & $\log \mathrm{k}_{1} / \mathrm{k}_{2}$ & $\pi$ & $\mathrm{L}$ & $\mathrm{B}_{1}$ & $\mathrm{~B}_{4}$ & $\mathrm{~F}$ & $\mathrm{R}$ & $\sigma_{\mathrm{p}}$ \\
\hline $\mathbf{1 a}$ & $\mathrm{Et}$ & 1.525 & 0.544 & 0.981 & 1.02 & 4.11 & 1.52 & 2.97 & -0.05 & -0.1 & -0.15 \\
$\mathbf{1 b}$ & $\mathrm{F}$ & 1.823 & 0.519 & 1.304 & 0.14 & 2.65 & 1.35 & 1.35 & 0.43 & -0.34 & 0.06 \\
$\mathbf{1 c}$ & $\mathrm{Me}$ & 1.870 & 0.505 & 1.365 & 0.56 & 3.00 & 1.52 & 2.04 & -0.04 & -0.13 & -0.17 \\
$\mathbf{1 d}$ & $\mathrm{MeO}$ & 1.299 & 0.270 & 1.029 & -0.02 & 3.98 & 1.35 & 2.87 & 0.26 & -0.51 & -0.27 \\
$\mathbf{1 e}$ & $\mathrm{H}$ & 1.816 & -0.022 & 1.838 & 0.00 & 2.06 & 1.00 & 1.00 & 0.00 & 0.00 & 0.00 \\
$\mathbf{1 f}$ & $\mathrm{nPr}$ & 1.362 & -0.066 & 1.428 & 1.55 & 5.05 & 1.52 & 3.49 & -0.06 & -0.08 & -0.13 \\
$\mathbf{1 g}$ & $\mathrm{Cl}$ & 1.328 & -0.149 & 1.477 & 0.71 & 3.52 & 1.8 & 1.8 & 0.41 & -0.15 & 0.23 \\
$\mathbf{1 h}$ & $\left(\mathrm{CH}_{2}\right)_{2} \mathrm{NH}_{2}$ & 0.699 & -1.000 & 1.699 & -0.76 & 4.8 & 1.52 & 3.4 & -0.06 & 0.00 & -0.06 \\
$\mathbf{1 i}$ & $\mathrm{CH}_{2} \mathrm{CN}$ & 1.107 & -0.658 & 1.765 & -0.57 & 3.99 & 1.52 & 4.12 & 0.21 & -0.18 & 0.01 \\
$\mathbf{1 j}$ & $\mathrm{OH}$ & 0.924 & -1.699 & 2.623 & -0.67 & 2.74 & 1.35 & 1.93 & 0.29 & -0.64 & -0.37 \\
$\mathbf{1 k}$ & $\mathrm{NO}_{2}$ & $<-3.0$ & $(-3.0)$ & - & -0.28 & 3.44 & 1.7 & 2.44 & 0.67 & 0.16 & 0.78 \\
$\mathbf{1 l}$ & $\mathrm{CN}_{\mathbf{1}}$ & $<-3.0$ & $(-3.0)$ & - & -0.57 & 4.23 & 1.6 & 1.6 & 0.51 & 0.19 & 0.66 \\
$\mathbf{1 m}$ & $\mathrm{CF}_{3}$ & $<-3.0$ & $(-3.0)$ & - & 0.88 & 3.3 & 1.98 & 2.61 & 0.38 & 0.19 & 0.54 \\
\hline
\end{tabular}

\section{Oxidase activity $\left(\log \mathbf{k}_{1}\right)$}

Three of the catechols $\mathbf{1 k - m}$ were not oxidised by tyrosinase and had no inhibitory effect as shown by subsequent oxidation of 4-methylcatechol. They were not included in the analysis of oxidase activity. A preliminary analysis of the other ten compounds $\mathbf{1 a - j}$ revealed the significant relationship summarised in Equation 1, where $\pi$ is the substituent hydrophobic constant and L is the Verloop STERIMOL substituent length parameter. No evidence of correlation with the other substituent parameters shown in Table 1 was found. Using Equation 1 the oxidation rate for catechol $\mathbf{1} \mathbf{j}$ is high [ $\log \mathrm{k}_{1}$ (calc.) 1.311]. Since the rate constants for catechol $\mathbf{1} \mathbf{j}$ were obtained at $\mathrm{pH} 3.5$, whereas all other compounds were measured at $\mathrm{pH} \mathrm{6.75,} \mathrm{we} \mathrm{investigated} \mathrm{the} \mathrm{exclusion}$ of this derivative. Equation 2 shows the relationship without catechol 1j. Although the correlation is slightly improved, leaving out this derivative does not significantly change the relationship.

$$
\begin{aligned}
& \log \mathrm{k}_{1}=0.364( \pm 0.097) \pi-0.297( \pm 0.077) \mathrm{L}+2.369 \\
& \mathrm{n}=10, r=0.876, s=0.216, F=11.52, p=0.006
\end{aligned}
$$




$$
\begin{aligned}
& \log \mathrm{k}_{1}=0.288( \pm 0.067) \pi-0.336( \pm 0.051) \mathrm{L}+2.578 \\
& \mathrm{n}=9, r=0.949, \mathrm{~s}=0.140, F=27.22, p=0.001
\end{aligned}
$$

We interpret Equation 1 as indicating that for rapid catechol oxidation by mushroom tyrosinase a short (L) and hydrophobic $(\pi)$ substituent $\mathrm{R}$ is required. This provides a quantitative summary of the qualitative observation that catechol $1 \mathbf{e}(\mathrm{R}=\mathrm{H})$, 4-fluorocatechol $\mathbf{1 b}(\mathrm{R}=\mathrm{F})$ and 4-methylcatechol 1c $\left(\mathrm{R}=\mathrm{CH}_{3}\right)$ have the fastest oxidation rates and larger substituents or hydrophilic substituents result in slower oxidation.

If $\pi$ and $\mathrm{L}$ were the only substituent properties that determined the rate of catechol oxidation by tyrosinase, the catechols $1 \mathbf{k}-\mathbf{m}\left(\mathrm{R}=\mathrm{NO}_{2}, \mathrm{CN}, \mathrm{CF}_{3}\right)$ would have log $\mathrm{k}_{1}$ values in the range 0.91.7 based on Equation 1. Clearly there is an additional effect in these derivatives, which it is reasonable to suppose is an electronic effect, since $\mathrm{NO}_{2}, \mathrm{CN}$ and $\mathrm{CF}_{3}$ are strongly electronwithdrawing $\left(\sigma_{\mathrm{p}}\right.$ 0.5-0.8). It is well established that strongly electron-withdrawing substituents make catechols more difficult to oxidize and we have encountered similar effects in our studies of the autoactivation mechanism of tyrosinase. ${ }^{12}$

\section{Tyrosinase inactivation $\left(\log \mathbf{k}_{2}\right)$}

An analysis of the ten catechols that inhibit tyrosinase (1a-j, Table 1) identified a significant parabolic relationship between $\log \mathrm{k}_{2}$ and $\pi$ (Equation 3). This relationship suggests an optimum substituent hydrophobicity $\left(\pi_{\mathrm{opt}} \sim 0.7\right)$. Without the $\pi^{2}$ term a significant correlation is not observed. We have systematically searched for steric parameters, including $\mathrm{L}, \mathrm{B}_{1}, \mathrm{~B}_{4}$ and $\mathrm{MR}$, that give a correlation without the use of $\pi^{2}$ but no other significant correlation was found. Leaving out catechol $\mathbf{1 j}(\mathrm{R}=\mathrm{OH})$, for the reasons discussed above, gave Equation 4 and did not significantly change the relationship.

$$
\begin{aligned}
& \log \mathrm{k}_{2}=1.143( \pm 0.229) \pi-0.819( \pm 0.243) \pi^{2}+0.061 \\
& \mathrm{n}=10, r=0.883, s=0.393, F=12.44, p=0.005 \\
& \log \mathrm{k}_{2}=0.900( \pm 0.194) \pi-0.670( \pm 0.190) \pi^{2}+0.116 \\
& \mathrm{n}=9, r=0.884, s=0.292, F=10.77, p=0.010
\end{aligned}
$$

Apart from the hydroxy derivative $\mathbf{1 j}$ discussed above, the only other outlier in Equation 3 is the chloro derivative $1 \mathrm{~g}$ [ $\log \mathrm{k}_{2}$ (obs.) -0.149] which is significantly less active as an inhibitor than predicted [log $\mathrm{k}_{2}$ (calc.) 0.463]. This low activity is surprising since this substituent has optimal hydrophobicity based on Equation $3\left[\pi_{\mathrm{opt}} 0.7 ; \pi_{\mathrm{Cl}} 0.71\right]$. A possible reason for this observation is that an electronic effect is becoming significant. The electron-withdrawing power of $\mathrm{Cl}$ (measured by $\sigma_{\mathrm{p}}$ ) is much greater than that of the other substituents in the set 1a-j. However, $\mathrm{Cl}\left(\sigma_{\mathrm{p}} 0.23\right)$ is not as electron withdrawing as $\mathrm{NO}_{2}\left(\sigma_{\mathrm{p}} 0.78\right), \mathrm{CN}\left(\sigma_{\mathrm{p}} 0.66\right)$ and $\mathrm{CF}_{3}\left(\sigma_{\mathrm{p}}\right.$ 0.54 ), and for this reason it may not show complete lack of activity like the $\mathrm{NO}_{2}, \mathrm{CN}$ and $\mathrm{CF}_{3}$ derivatives 1k-m. To further investigate this apparent electronic effect, we made the assumption 
that the $\mathrm{NO}_{2}, \mathrm{CN}$ and $\mathrm{CF}_{3}$ derivatives are very weakly active and that $\log \mathrm{k}_{2}=-3.0$, which is below the lower limit of measurement. Using these values for compounds $1 \mathbf{k}-\mathbf{m}$, multiple regression gave the correlation shown in Equation 5. In this relationship the $\pi$ and $\pi^{2}$ terms are essentially the same as in Equations 3 but now the $\sigma_{\mathrm{p}}$ term is also significant and the $\mathrm{Cl}$ derivative is no longer an outlier. Leaving out catechol $\mathbf{1} \mathbf{j}$ improves the correlation (Equation 6).

$$
\begin{aligned}
& \log \mathrm{k}_{2}=1.129( \pm 0.416) \pi-0.956( \pm 0.481) \pi^{2}-3.000( \pm 0.638) \sigma_{\mathrm{p}}-0.239 \\
& \mathrm{n}=13, r=0.873, s=0.786, F=9.58, p=0.004 \\
& \log \mathrm{k}_{2}=0.677( \pm 0.330) \pi-0.707( \pm 0.353) \pi^{2}-3.634( \pm 0.499) \sigma_{\mathrm{p}}-0.076 \\
& \mathrm{n}=12, r=0.942, s=0.562, F=21.07, p=0.0004
\end{aligned}
$$

\section{Conclusions}

The analysis described above shows that the substituent properties that influence the rate of tyrosinase oxidation of catechols to ortho-quinones (Equation 1) are different from the properties that influence the rate of inactivation of tyrosinase by catechols (Equation 3). This is in agreement with our proposal that during oxidation (oxidase activity) both catechol oxygen atoms bind to the coppers in the active site whereas for inactivation (mono-oxygenase activity) only one catechol oxygen atom binds to copper. ${ }^{8}$ The ring substituents therefore present to different regions of the enzyme during the competing transformations.

The observed relative rates of oxidation $\left(\log \mathrm{k}_{1} / \mathrm{k}_{2}\right)$ are given in Table 1. Using Equations 1 and 3, the relative rates of oxidation $\left(\log \mathrm{k}_{1} / \mathrm{k}_{2}\right)$ can be expressed as Equation 7 .

$$
\log \mathrm{k}_{1} / \mathrm{k}_{2}=\log \mathrm{k}_{1}-\log \mathrm{k}_{2}=-0.779 \pi+0.819 \pi^{2}-0.297 \mathrm{~L}+2.308
$$

Based on Equation 7, optimum oxidation relative to inactivation will occur with short substituents (ideally $L=0$ ) that also have $\pi \leq 0$ or $\pi>0.95$. Few substituents can fulfil both these conditions. In accord with these requirements, the parent catechol 1e $\left(\mathrm{L}=2.06, \pi_{\mathrm{H}}=0\right)$ (Table 1) has a good turnover [log $\mathrm{k}_{1} / \mathrm{k}_{2}$ : (calc) 1.696, (obs) 1.838]. In spite of experimental difficulties with measurements, the derivative $\mathbf{1} \mathbf{j}$ with the small hydrophilic $\mathrm{OH}$ substituent $\left(\mathrm{L}=2.74, \pi_{\mathrm{OH}}=\right.$ -0.67 ), in agreement with Equation 7 , has the slowest relative rate of inactivation $\left[\log \mathrm{k}_{1} / \mathrm{k}_{2}\right.$ : (calc) 2.386, (obs) 2.623]. There are few other substituents with $\mathrm{L}<3 .{ }^{14}$ In principle 4aminocatechol $1\left(\mathrm{R}=\mathrm{NH}_{2}\right)$ has $\log \mathrm{k}_{1} / \mathrm{k}_{2}$ (calc) 3.635 , which would make it highly selective. However, 4-aminocatechol is very reactive and readily undergoes non-enzymic oxidation in the presence of dioxygen. Potentially the protonated form $\left(\mathrm{R}=\mathrm{NH}_{3}{ }^{+}\right)$should also be selective [log $\mathrm{k}_{1} / \mathrm{k}_{2}$ : (calc) $>10$ ] based on Equation 7 but this substituent is also electron withdrawing $\left(\sigma_{\mathrm{p}} \sim 0.6\right)$ and, like $\mathrm{NO}_{2}, \mathrm{CF}_{3}$ and $\mathrm{CN}$ (catechols 1k-m), can be expected to be inactive due to the previously discussed electronic effect. 


\section{Experimental Section}

Biological activity. The experimental data were obtained using polarimetric analysis of the initial rate and the total oxygen utilization by tyrosinase under standard conditions as previously described. ${ }^{12}$ The apparatus consisted of a $3.65 \mathrm{~mL}$ quartz cuvette fitted with a Clark-type electrode, and concurrent readings made using a Yellow Springs Instruments (Model 5300) polarimeter and a Hewlett-Packard diode array spectrophotometer (Model 8452A). Tyrosinase (ex Agaricus bisporus) was obtained from Sigma-Aldrich and made up in $0.1 \mathrm{M}$ phosphate buffer ( $\mathrm{pH}$ 7.4) and stored in $5 \mathrm{~mL}$ aliquots at $-20^{\circ} \mathrm{C}$ prior to use. The compounds tested were obtained from Sigma-Aldrich or synthesised using literature procedures and were made up freshly in distilled water. The substrate solutions were added to the incubation mixture in $0.1 \mathrm{M}$ phosphate buffer ( $\mathrm{pH}$ 6.75) with the exception of catechol $\mathbf{1} \mathbf{j}$ (Table 1) which was incubated at $\mathrm{pH} 3.5$ because of rapid autoxidation under the standard conditions. The assays were performed with a substrate concentration of $820 \mu \mathrm{M}$ with enzyme concentrations in the range 1-10 (Sigma) units per $\mathrm{mL}$. The total oxygen utilization was calculated as nanomoles oxygen per unit enzyme from which the rate constants $\left(\mathrm{k}_{1}\right.$ and $\left.\mathrm{k}_{2}\right)$ were determined as previously described. ${ }^{6}$ The rate constants for compounds $1 \mathbf{a}-\mathbf{g}, \mathbf{1} \mathbf{j}$ and $\mathbf{1} \mathbf{k}$ (Table 1) are taken from reference 6 . The rate constants for compounds $\mathbf{1 h}, \mathbf{1 i}, \mathbf{1 l}$ and $\mathbf{1 m}$ have not previously been reported.

\section{Regression analysis}

The regression analyses were performed using the program OriginPro 8 SR4 (version 8.095) (OriginLab Corporation, Northhampton, MA 01060, USA). Values for the substituent parameters $\pi, \mathrm{MR}, \mathrm{F}, \mathrm{R}$, and $\sigma_{\mathrm{p}}$ were taken from reference 13 and the Verloop STERIMOL parameters $\mathrm{L}, \mathrm{B}_{1}$ and $\mathrm{B}_{4}$ were taken from reference 14 .

\section{References}

1. Decker, H.; Terwilliger, N. J. Exp. Biol. 2000, 203, 1777.

2. Land, E. J.; Ramsden, C. A.; Riley, P. A. Acc. Chem. Res. 2003, 36, 300.

3. Jordan, A. M.; Khan, T. H.; Malkin, H.; Osborn, H. M.; Photiou, A.; Riley, P. A. Bioorg. Med. Chem. 2001, 6, 1549.

4. Nelson, J. M.; Dawson, C. R. Adv. Enzymology 1944, 4, 99.

5. Asimov, I.; Dawson, C. R. J. Am. Chem. Soc. 1950, 72, 820.

6. Land, E. J.; Ramsden, C. A.; Riley, P. A. Tohoku J. Exp. Med. 2007, 212, 341.

7. Land, E. J.; Ramsden, C. A.; Riley, P. A.; Stratford, M. R. L. Tohoku J. Exp. Med. 2008, 216, 231.

8. Ramsden, C. A.; Stratford, M. R. L.; Riley, P. A. Org. Biomol. Chem. 2009, 7, 3388.

9. Ramsden, C. A.; Riley, P. A Arkivoc 2010, (i), 260. 
10. Dietler, C.; Lerch, K. In Oxidases and Related Redox Systems; King, T. E.; Mason, H. S.; Morrison, M. Eds.; Pergamon Press: New York, 1982, pp 305-317.

11. Pleiss, M. A.; Unger, S. H. In Comprehensive Medicinal Chemistry; Ramsden, C. A. Vol. Ed.; Pergamon Press: Oxford, 1990; Vol. 4, p 561.

12. Cooksey, C. J.; Garratt, P. J.; Land, E. J.; Pavel, S.; Ramsden, C. A.; Riley, P. A.; Smit, N. P. M. J. Biol. Chem. 1997, 272, 26226.

13. Hansch, C.; Leo, A. Substituent Constants for Correlation Analysis in Chemistry and Biology, John Wiley \& Sons, Inc.: New York, 1979.

14. Verloop, A.; Hoogenstraaten, W.; Tipker J. In Drug Design, Ariens E. J. Ed.; Academic Press: New York, 1976; Vol. VII, pp 165-185. 